\title{
The evaluation of java fine flavor cocoa propagation through somatic embryogenesis technique for germplasm preservation
}

\author{
Sulistyani Pancaningtyas* \\ Indonesian Coffee and Cocoa Research Institute, Jl. PB. Sudirman, 90, Jember 68118, Indonesia
}

\begin{abstract}
Somatic embryogenesis is one of the newest technology that applied for the mass production of cocoa. This research aims to evaluate the regeneration rate of somatic embryos through somatic embryogenesis propagation techniques on java fine flavor cocoa. Cultivars in this study are ICCRI 01, ICCRI 02, DR 1, DR 2, DRC 16, DR 38, PNT 16, and PNT 30. Observations include parameters to determine the percentage of primary callus and embryogenic callus formation and the number of somatic embryos produced. Based on data, the ability of callus to produce primary embryos is highly dependent on plant cultivars and explant sources. Five cultivars showed a higher regeneration rate using explants from the petal part, while the rest showed a higher regeneration rate using explants from the staminode section. Embryogenic callus from each cacao cultivar has the same basic structure: a nodular friable structure consisting of many embryonic cells. Some fine flavor cacao cultivars that were able to produce callus and primary somatic embryos could not produce secondary somatic embryos and plantlets. However, two cultivars, which had low potential in producing primary embryos, had the high ability to produce secondary somatic embryos and develop into plantlets.
\end{abstract}

\section{Introduction}

Cocoa from the Theobroma cacao (L.) genus, known for the raw material of chocolate, was cultivated due to the critical value of the seeds [1]. Two essential groups of cocoa contribute to chocolate industries, namely fine flavor cocoa and bulk cocoa. Fine flavor cocoa is recommended to smallholders or farmers cultivate cocoa. In general, the fine flavor of cocoa is produced from the Criollo or Trinitario types, while the Bulk comes from the Forastero type [2,3]. This type of cocoa has high productivity and is relatively easy to cultivate. Meanwhile, fine flavor cocoa is generally grown by large plantations and has excellence in aroma and taste. Fine flavor cocoa from Indonesia has been known as Java Fine Flavor Cocoa, although the amount of production has continued to decline in the last decade. This type of cocoa requires intensive cultivation techniques so that fine flavor cacao is only cultivated by the State Plantation Company, which is currently limited to PTPN XII in East Java.

* Corresponding author: listya.1606@gmail.com 
The Spaniards first carried out the introduction of cacao plants to Indonesia from Venezuela in early 1560. The introduced varieties were "Criollo Venezuela," better known as fine flavor cocoa in Venezuela and subsequently spread to Samoa, Sri Lanka, Madagascar, and Indonesia. This variety was brought to Indonesia via Caracas and cultivated in northern Sulawesi (Minahasa), intended only for consumption. Cocoa breeding in Indonesia developed in 1912 at the Djati Renggo Plantation, Central Java, has produced selected fine flavor cocoa clones, which were later named "Djati Renggo clones" (DR clones). These clones turned out to be quite susceptible to pests and diseases, particularly VSD disease [4]. Motamayor [3] also stated that cacao of the Criollo variety is susceptible to fungal infection and insect attack. Over time, its aromatic qualities diminish due to various crossovers with genotypes of different genetic origins, leading to hybrids with higher disease resistance.

Fine flavor cocoa has a relatively small contribution in fulfilling world production supply, only $5 \%$ of world cocoa production. However, fine flavor cacao has recently increased demand because chocolate producers use it for high-end products or specific markets [5]. Ecuador and Trinidad \& Tobago are the leading producers of fine flavor cocoa, contribute more than five percent per year to world production. Indonesia only contributes $0.2 \%$ as a producer of fine flavor cocoa [6]. Fine flavor cocoa is a type of cocoa that has a high and unique taste (fine flavor cocoa), therefore has very good price. With the increase in world demand for high-quality cocoa, the opportunity for mass development of fine flavor cocoa will be very profitable in market utilization.

The priority of fine flavor cocoa breeding is currently directed at cocoa with special taste, tolerant to disease (Vascular Streak Dieback), high productivity, and is genetically stable. Based on the selection results of cocoa breeders, nine genotypes of fine flavor cocoa have been obtained, which have superior disease tolerant properties, high yield potential, and good yield quality, including PNT-8, PNT-12, PNT-16, PNT-18, PNT-30, PNT. -37, PNT-38 and PNT-39 [7]. Fine flavor cocoa plant materials available in Indonesia are DR 1, DR 2, DR 38, DRC 16 with a productivity level of 1-1.5 tonnes of dry beans/ha/year of recommended clones, and new clones are ICCRI 1 and ICCRI 2 with potential productivity of 2 tonnes/ha/year [8]. In addition to fulfilling national production, the propagation of fine flavor cocoa is also carried out to maintain the biodiversity of germplasm because the number is decreasing due to disease attacks. Fine flavor cocoa can be reproduced both generatively and vegetatively.

One current alternative mass propagation technology for cocoa is in vitro propagation through the somatic embryogenesis (SE) technique. One of the advantages of in vitro propagation is to assist genetic conservation in preserving endangered plants. According to Pancaningtyas [9], cocoa somatic embryogenesis is a propagation technique that produces primary embryos from cacao flower parts (staminode and petal). This technique has several advantages over conventional propagation techniques for large-scale plant propagation while maintaining genetic stability and integrity. Plants with a uniform genotype are obtained in large numbers and in a short time $[10,11]$. This research aims to evaluate the regeneration rate of somatic embryos through somatic embryogenesis propagation techniques on java fine flavor cocoa. 


\section{Materials and methods}

This research was conducted at the Biotechnology Laboratory of the Indonesian Coffee and Cocoa Research Institute and PTPN XII Plantation from September 2018 to December 2020. Research on cocoa propagation through the Somatic embryogenesis technique was carried out in several stages: mother boom selection, explants collection, flower bud induction, primary embryo and embryogenic callus initiation, secondary embryo production, and germination. This study using the procedure for the propagation of Bulk cacao.

The cultivars used in this study are ICCRI 01, ICCRI 02, DR 1, DR 2, DRC 16, DR 38, PNT 16, and PNT 30. For each clone used 500 flower buds. The parameters observed in this study were the percentage of callus formation, the percentage of primary somatic embryo formation, the percentage of embryogenic callus formation, the number of somatic embryos, and the percentage of somatic embryos that developed into plantlets. The somatic embryogenesis process carried out in this study are:

\subsection{Selection of mother boom}

Mother boom selection for propagation material is an essential factor before starting the Somatic Embryogenesis process in the laboratory. Through a selection process by plant breeders, superior plants are propagated vegetatively through somatic embryogenesis. In this propagation technique, cocoa seedlings are phenotypically similar to plants derived from seeds [12].

\subsection{Sterilization and induction of explants}

Sterilization is carried out to obtain sterile explants free from a microorganism (bacteria or fungi). The flower part explants were sterilized using 30\% sodium hypochlorite solution and $70 \%$ alcohol. The sterilized flower explants were placed in a sterile Petri dish of 4-10 flowers depending on the ability of each individual to induce, to avoid desiccating the surface of the flowers after cutting. Next, cut the base of the flower $(1 / 3$ of the length of the flower from the base) using a sterile scalpel. Separate the petals and staminode from the stamen and pistil using tweezers. Cover the Petri dish tightly using parafilm or plastic wrap and keep it in the dark for $3-4$ weeks at $20-25^{\circ} \mathrm{C}$. Callus formation will generally begin at the end of this stage.

\subsection{Primary embryo production}

After four weeks, transfer the explants to somatic embryo formation media supplemented with cytokinin hormones, then incubate for 4-8 weeks in the dark with two sub-cultures. Callus formation is an early stage of somatic embryogenesis. There are two types of callus obtained at this stage. The first is an enlarged and white cell, usually called a compact callus. Primary embryos generally will not develop from this type of callus. The second type is cells that divide and are light brown or dark brown with a friable structure (crumbs). Such cell clusters can produce primary embryos [10]. The medium was a combination of MS and DKW basalt media with the addition of amino acids, vitamins, $2.4 \mathrm{D} 1 \mathrm{mg} / 1$, kinetin $0.25 \mathrm{mg} / 1$, gelrite, and glucose. 


\subsection{Formation of secondary embryogenic callus}

Primary embryos that have been obtained in the previous stage are induced again to produce embryogenic callus, that is, callus which has the potential to produce embryos, which will be used to produce secondary embryos. Primary embryos are selected that have fully developed, namely in the cotyledon phase, incubated for eight weeks in dark conditions at $25^{\circ} \mathrm{C}$. The callus formed from the primary embryo is then sub-cultured on a planting medium with a balanced hormone to assist the embryogenic callus formation process. Secondary embryogenesis is used to increase the number and quality of the resulting somatic embryos [10].

\subsection{Embryogenic callus multiplication}

The embryogenic callus that had been formed from the previous induction process was then sub-cultured into multiplication media. Multiplication media is a medium that is rich in auxin hormones to increase cell division and proliferation, thereby increasing the multiplication rate. The explants were incubated in the dark and sub-cultured every three weeks. Each cluster has an average ability to multiply about 3 to 5 times that of the initial cluster with callus wet weight parameters. The medium used was a combination of MS and DKW media with the addition of amino acids, vitamins, $2.4 \mathrm{D} 1.25 \mathrm{mg} / 1$, kinetin $0.25 \mathrm{mg}$ $/ 1$, gelrite, and glucose.

\subsection{Embryo development}

This stage is a process to induced somatic embryos derived from secondary embryogenic callus. Embryogenic callus from multiplication was sub-cultured on an expression medium. This process was incubated for four weeks in dark conditions. The characteristics of a perfect embryo that are ready for harvest are those in the torpedo-cotyledon phase. There are variations in the somatic embryo growth at this stage, including the globular phase to the cotyledon phase. The embryos at the torpedo phase and the cotyledon phase were subcultured on the same media. The medium used was a combination of MS and DKW media with the addition of amino acids, vitamins, adenine $0.025 \mathrm{mg} / 1$, gelrite, and glucose.

\subsection{Germination}

The fully formed embryos (torpedo-cotyledon phase) were sub-cultured to maturation media to extend the size of the embryos to embryos with a cotyledon phase of $\pm 2 \mathrm{~cm}$. This process was incubated for 2-3 weeks in solid media. The embryo performance in this phase is that the embryo will grow lengthwise, accompanied by the emergence of root candidates (root primordia). Cultures were incubated at 16/8 hours photoperiod. The final result at this stage is the cotyledon phase embryo that is ready to be germinated. The medium used was MS and DKW media with amino acids, vitamins, gellan gum, and sucrose.

\section{Results and discussion}

In developing cocoa through somatic embryogenesis, selecting initial explants as propagation material is essential in determining somatic embryos induction into plantlets. The role of the growth medium is one of the critical factors in supporting the continuity of plant growth at each stage. The medium used contains five main components, namely 
inorganic compounds, carbon sources, vitamins, growth regulators, and organic supplements.

\subsection{Callus Initiation}

The ability of each explant to respond to the embryogenesis process is strongly influenced by the physiological and genetic conditions of the explants (Fig. 1). The selection of explant sources (petal and staminode explants from the cacao flower) also influenced the initiation of the embryogenesis process in each cultivar. All superior cocoa clones were propagated by somatic embryogenesis using existing media (according to the somatic embryogenesis technique protocol developed by ICCRI). Some fine flavor cacao cultivars are more difficult to propagate in vitro than bulk cacao. However, some cultivars have better embryogenic callus formation rates than others. So it is necessary to optimize the media in multiplication, expression, and plantlet development. The study results showed that PNT 30, ICCRI 01, and DR 1 cultivars showed a high callus formation $(100 \%$, $98,33 \%$, and $88,07 \%$ ) from petal parts compared to other cultivars of fine flavor cacao (Fig. 1). DR 38, ICCRI 02, and DR 2 cultivars showed a better response to callus formation from staminode than petal $(73,95 \%, 70 \%$, and $29,97 \%)$.

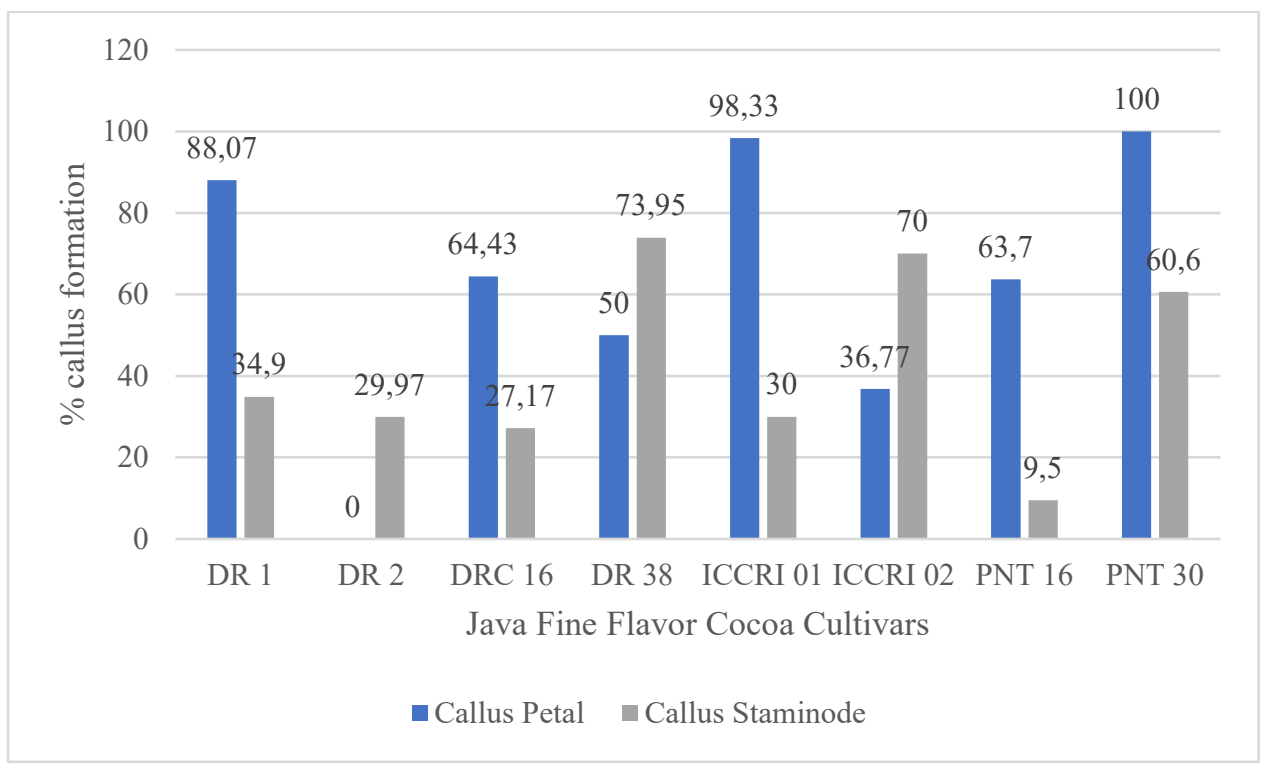

Fig.1. Percentage of callus formation of eight java fine flavor cocoa cultivars that used two parts of the cocoa flower as explant (petal and staminode)

Primary somatic embryos from each cacao cultivar, either the petals or staminodes, had the same shape and color as the primary embryos from the PNT 16 cultivar below (Fig. 2). The difference is in the number of embryos produced in each cluster and their ability to produce secondary embryogenic callus. 


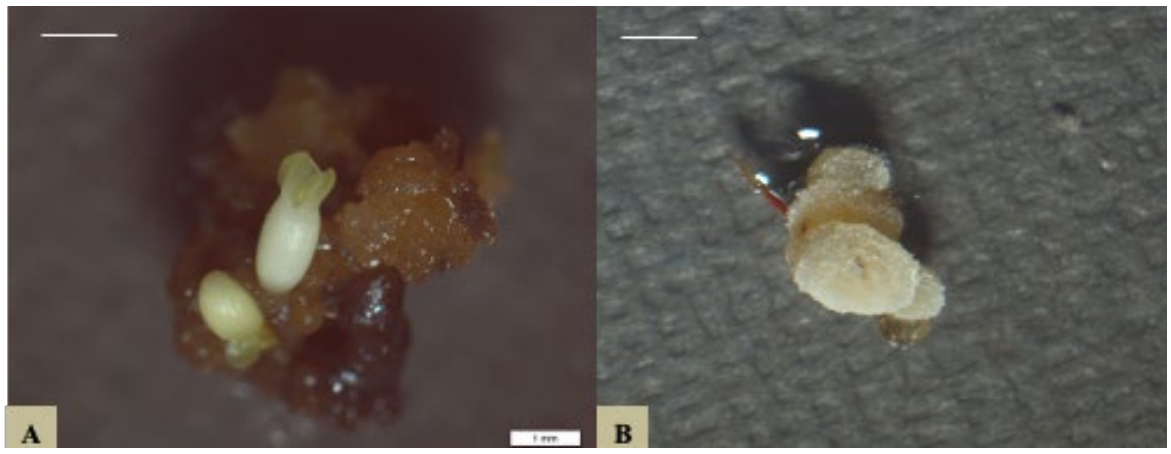

Fig. 2. The primary somatic embryo of PNT 16 cultivar from petal section. A. primary somatic embryos from petal section, B. Callus from staminode section. Bar $=1 \mathrm{~mm}$.

The ability of callus to produce primary embryos is highly dependent on plant cultivars and explant sources. Besides having high callus formation ability, ICCRI 01 also produces high primary embryos (18.64\%) compared to other cultivars (Fig. 3). The rate of primary embryo formation was lower in the different cultivars, both on the petals and the staminode.

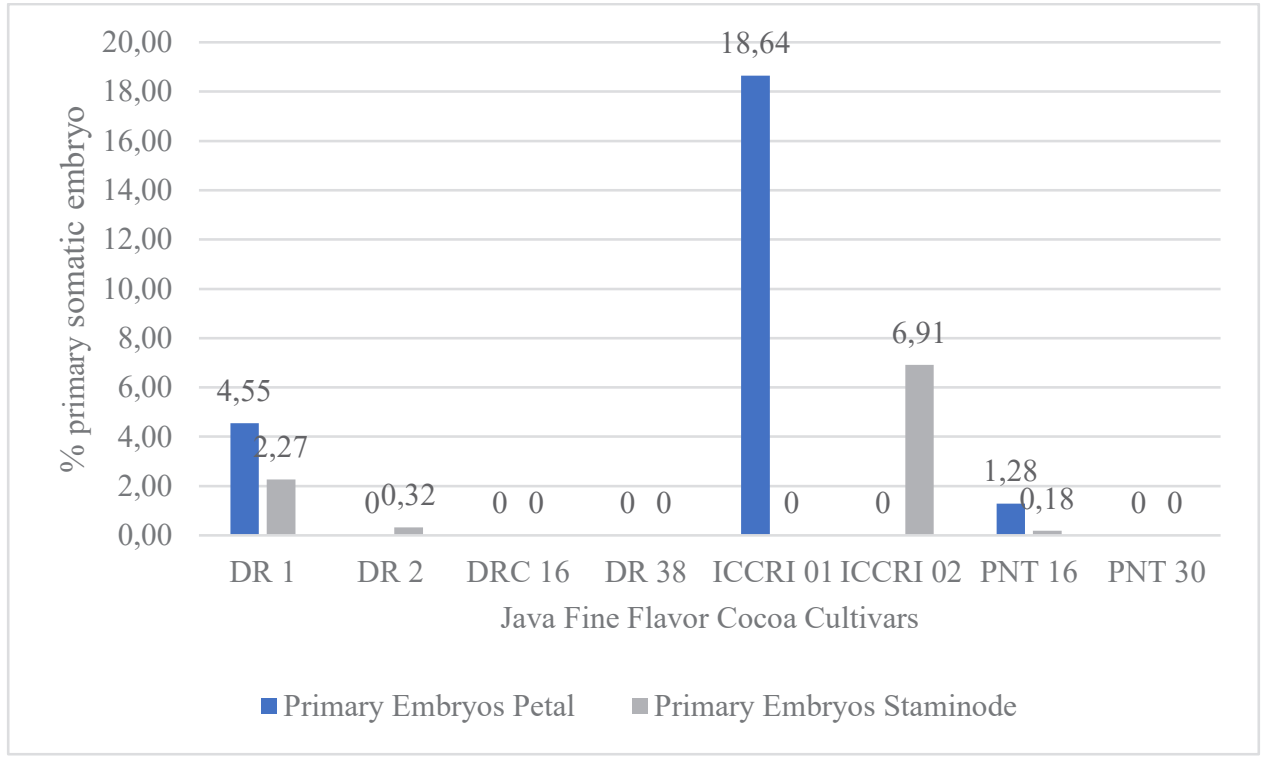

Fig. 3. Percentage of primary somatic embryo formation of eight java fine flavor cocoa cultivars

Primary embryos that have been obtained in the previous stage are induced again to produce embryogenic callus, that is, callus which has the potential to produce embryos, which will be used to produce secondary embryos. More somatic embryos will be produced through this process, and physiologically, secondary somatic embryos are better than primary somatic embryos in terms of performance in the field. Secondary embryogenesis is used to increase the number and quality of the resulting somatic embryos [10]. 


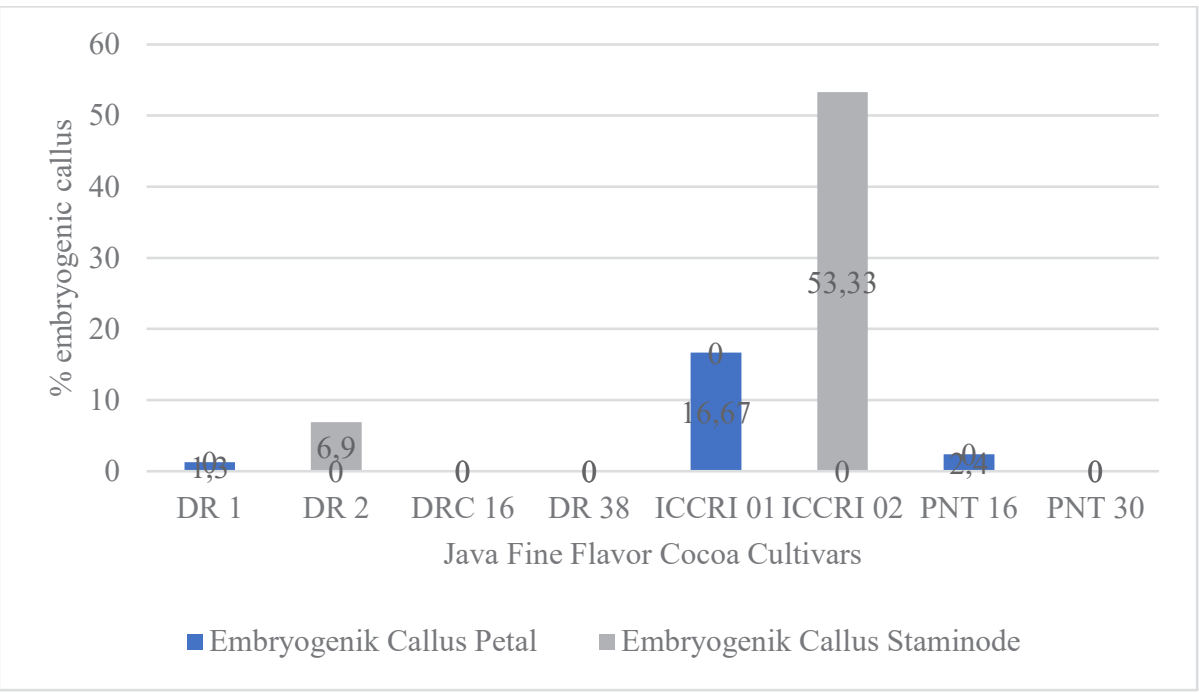

Fig. 4. Percentage of embryogenic callus of eight java fine flavor cocoa cultivars

Each cultivar of fine flavor cocoa showed a different response to the embryogenic callus formation. ICCRI 02 cultivar showed the best response in producing embryogenic callus from the staminode part (53.33\%), followed by ICCRI 01 from the petals $(16.67 \%)$ and DR $2(6.9 \%)$ from staminode (Fig. 4). Due to these differences in response, it is necessary to optimize the ability of explants to form embryogenic callus. These treatments include optimizing auxin and cytokinin hormones to initiate the embryogenesis process.

Embryogenic callus from each cacao cultivar has the same basic structure: a nodular friable structure consisting of many embryonic cells. Histologically, embryogenic callus showed parenchymal cells with high mitotic activity [13]. However, each of these cultivars showed a different color, for example, the DR2 cultivar had a brown embryogenic callus color while the ICCRI 02 cultivar had a yellowish-brown callus color (Fig. 5). The ability of embryogenic callus to proliferate or regenerate to form somatic embryos is highly dependent on the genotype, culture medium, growth regulators, and conditions during culture incubation.

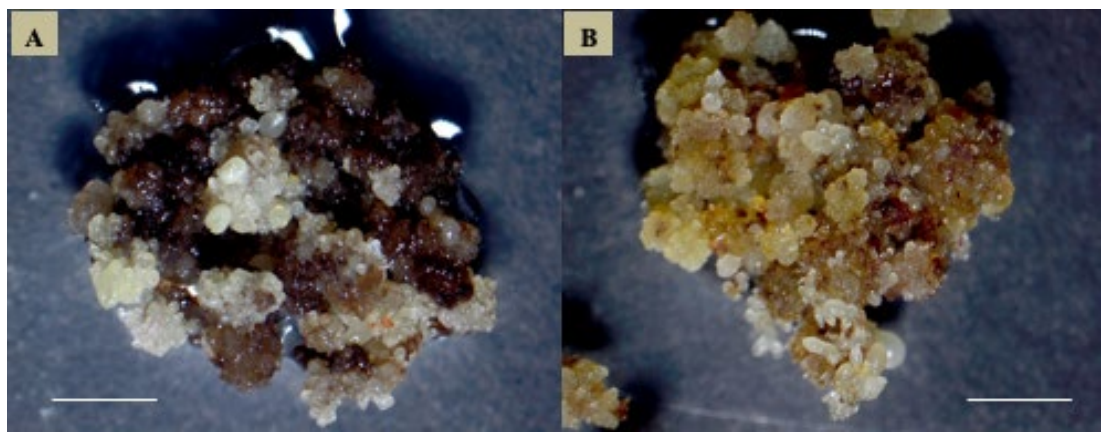

Fig. 5. Embryogenic callus. A. DR 2 cultivar from staminode section, B. ICCRI 02 cultivar from staminode section. Bar $=3 \mathrm{~mm}$.

The diversity of responses to somatic embryogenesis is due to differences in genotypes $[14,15,16]$. Benson [17] stated that the recalcitrant level of each genotype determines the totipotency of plant tissues. The ability of embryogenesis is also influenced by the concentration and distribution of polyphenolic compounds [18]. High concentrations of 
phenolic compounds are associated with non-regenerating responses of somatic embryos [19]. The high level of phenolic compounds is indicated by the occurrence of browning in the culture medium.

\subsection{Somatic embryo regeneration}

The difference in the ability of embryogenic callus cells to form somatic embryos on the regeneration medium is influenced by genetic factors and physiological factors of cells and the growth medium used. Embryogenic callus with nodular friable structure was transferred to the media for expression to form secondary somatic embryos. At this stage, the concentration of the hormone auxin is reduced or even eliminated to obtain a more uniform conversion rate of somatic embryos and a large number of somatic embryos. Somatic embryos for each cocoa cultivar have the same morphology, and the difference lies in the uniformity of phases in an embryogenic cluster. In the somatic embryo cluster of DR 2 and ICCRI 02 cultivars, globular, heart, torpedo, and even cotyledonary stages were found (Fig. 6)

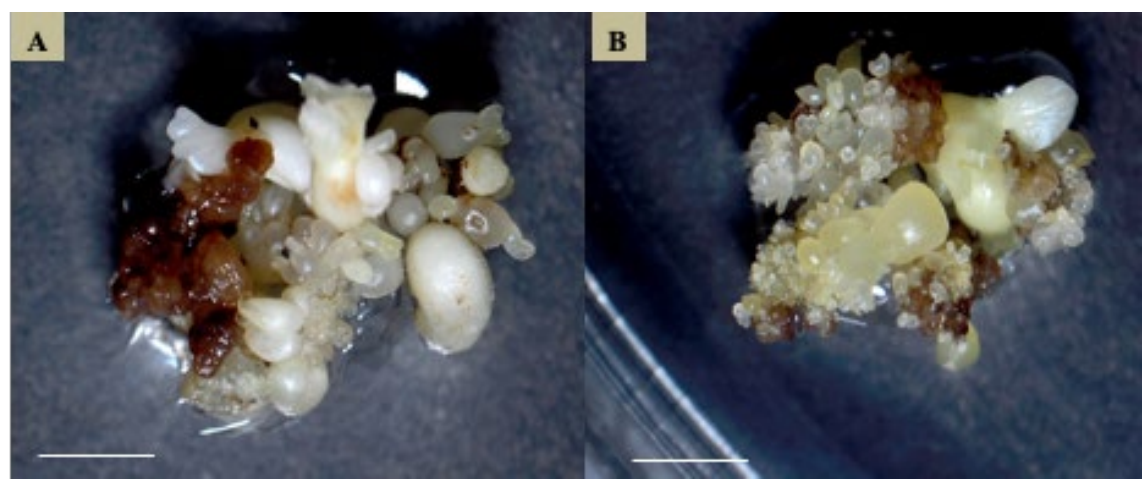

Fig. 6. Secondary somatic embryo development. A. DR 2 cultivars from staminode section, B. ICCRI 02 cultivars from staminode section. $\mathrm{Bar}=3 \mathrm{~mm}$.

ICCRI 02 cultivar from the staminode section showed the highest rate of somatic embryo development (61.54\%), followed by DR $2(40.29 \%)$, also from the staminode section compared to other clones (Fig. 7). Somatic embryos produced from ICCRI 02 and DR 2 cultivars showed better somatic embryo performance based on the number of normal somatic embryos produced at the regeneration (expression) stage. Normal somatic embryos have bipolar growth (having plumule and radicule), no evidence of vitrification, and no polyembryos in their development. These normal somatic embryos have a higher conversion rate to produce plantlets compared to abnormal somatic embryos. 


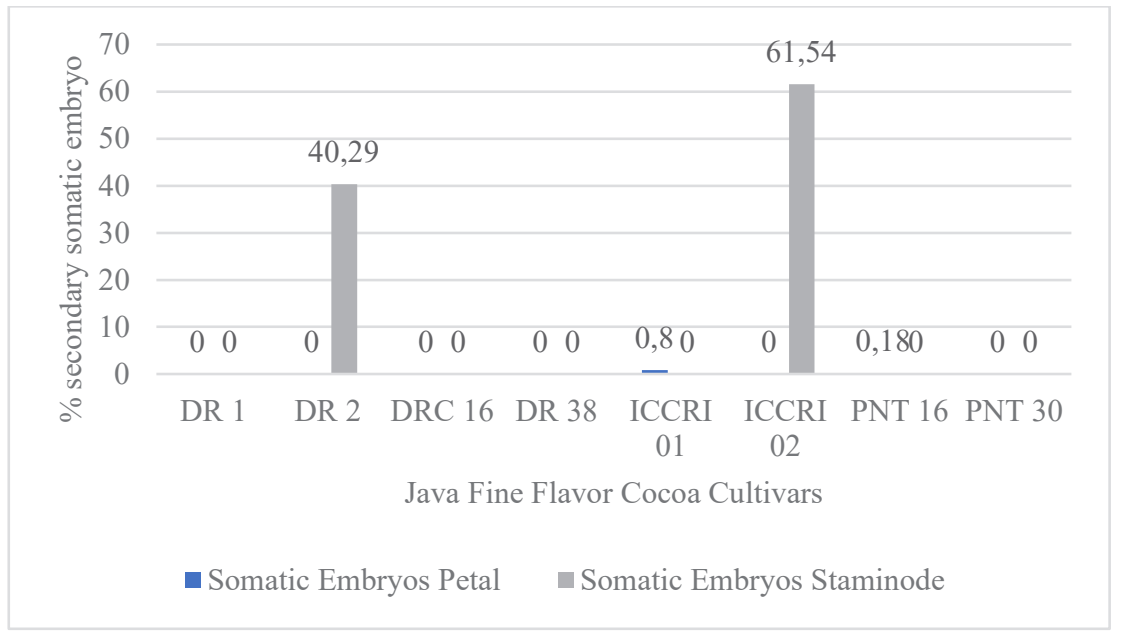

Fig. 7. Percentage of the secondary somatic embryo of eight java fine flavor cocoa cultivars

One factor influencing the low regeneration of secondary somatic embryos is the exudation of phenolic compounds in embryogenic callus cultures. Browning is one of the obstacles in vitro culture driven by the accumulation of phenolic compounds due to polyphenol oxidase (PPO) oxidation [20], these compounds can further inhibit the development of plant tissue in vitro. The addition of polyvinylpyrrolidone (PVP) and antioxidants such as ascorbic acid and citric acid is a way to inhibit the production of phenolic compounds or reduce their accumulation in tissue culture media [21]. The intensity of browning in culture is influenced by plant species and varieties, tissues or organs, plant development phase, tissue or organ age, nutritional media, and other tissue culture variables [22].

In a further development, DR 2 and ICCRI 02 cultivars showed the best viability in producing plantlets (45\% and 30.77\%). Meanwhile, other cultivars are still not able to regenerate to produce plantlets (Fig. 8).

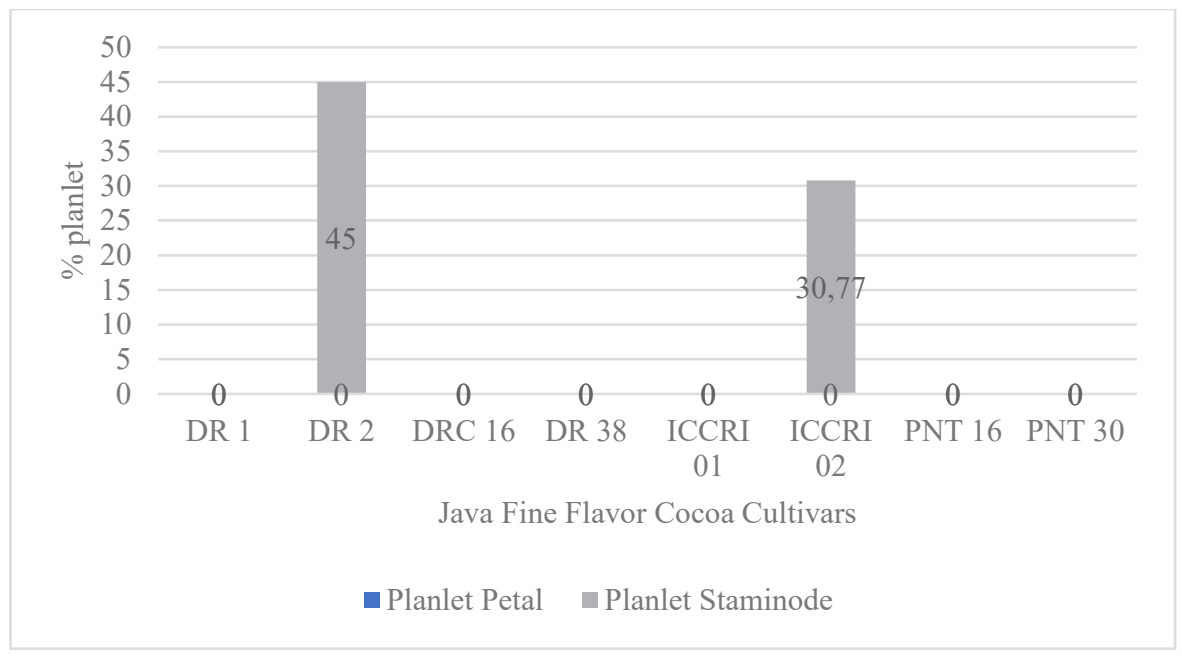

Fig. 8. Percentage of plantlet development of eight java fine flavor cocoa cultivars

The conversion rate of somatic embryos to become plantlets was relatively low compared to other cocoa cultivars from the Forastero type (bulk cocoa). Optimizing the 
growth media and microclimate of the plantlets during the growth period, such as light intensity, room humidity, and temperature, is necessary to increase the conversion ability. The development of this technology to date has produced plantlets with a conversion rate of $65 \%$ and a relatively low percentage of somaclonal variation [23]. Kouassi [16] and Modeste [24] have reported modifications related to growing media for somatic embryogenesis.

\section{Conclusions}

The ability of callus to produce primary embryos is highly dependent on plant cultivars and explant sources. DR1, DRC 16, ICCRI 01, PNT 16, and PNT 30 showed a higher regeneration rate using explants from the petal part, while the rest showed a higher regeneration rate using explants from the staminode section.

Embryogenic callus from each cacao cultivar has the same basic structure: a nodular friable structure consisting of many embryonic cells. Some fine flavor cacao cultivars that we're able to produce callus and primary somatic embryos, such as ICCRI 01 (98.33\% and $18.64 \%$ ), could not produce secondary somatic embryos and plantlets. However, ICCRI 02 and DR 2 cultivars, which had low potential in producing primary embryos, had the high ability to produce secondary somatic embryos $(61.54 \%, 40.29 \%)$ and develop into plantlets $(30.77 \%$ and $45 \%)$.

\section{References}

1. J.E. Kongor, M. Hinneh, D. Van de Walle, E.O. Afoakwa, P. Boeckx, K. Dewettinck, Food Res. Int. 82, 44-52 (2016)

2. J.C. Motamayor, A.M. Risterucci, P.A. Lopez, C.F. Ortiz, A. Moreno, Heredity. 89, 380-386 (2002)

3. J.C. Motamayor, A.M. Risterucci, M. Heath, C. Lanaud, Heredity. 91, 322-330 (2003)

4. A.W. Susilo, D. Zhang, L.A. Motilal, S. Mischke, L.W. Meinhardt, Trop. Agric. Dev. 55, 84-92 (2011)

5. ICCO, ICCO Panel Recognizes 23 Countries as Fine and Flavour Cocoa Exporters, https://www.icco.org/about-cocoa/fine-or-flavour-cocoa.html 2019 (2016)

6. ICCO, ICCO Quarterly Bulletin of Cocoa Statistics, XLIV (4), Cocoa year 2017/1018 (2019)

7. I.A. Sari, A.W. Susilo, Pelita Perkeb. (a Coffee Cocoa Res. Journal). 30, 2, 81-91 (2014)

8. Rubiyo, Buletin RISTRI. 4, 199-214 (2013)

9. S. Pancaningtyas, Pelita Perkeb. 29, 10-19 (2013)

10. S.N. Maximova, L. Alemanno, A.Young, N. Ferriere, A. Traore, M.J. Guiltinan, Vit. Cell. Dev. Biol. Plant. 38, 252-259 (2002)

11. A.K. Quainoo, B.I. Dwomo, J. Plant Stud. 1, $72-78$ (2012)

12. R.E. Litz, D.J. Gray, World J. Microbiol. Biotechnol. 11, 416-425 (1995)

13. S.A. Maciel, P.C.P.F. Junior, R.A. Silva, J.E. Scherwinski-Pereira, Act. Sci. Agr. 32, 2, 263-267 (2010)

14. L. Alemanno, M. Berthouly, N. Michaux-Ferrière, Plant Cell, Tissue Organ Cult. 46, 3, 187-194 (1996)

15. A.E. Issali, A. Traoré, J.A.K. Ngoran, K.E. Koffi, A. Sangare, J. Crop. Sci. Biotec. 11, 23-30 (2008) 
16. M.K. Kouassi, J. Kahia, C.N.G. Kouame, M.G. Tahi, E.K. Koffi, HortScience, 52, 142-145 (2017)

17. E.E. Benson, Vit. Cell Dev. Biol. Plant. 36, 141-148 (2000)

18. A.M.G. Rua, A.M.H. Ramirez, A.I.U. Trujillo, L.A. Garces, Acta Biológica Colomb. 21, 2, 335-345 (2016)

19. L. Alemanno, T. Ramos, A. Gargadenec, C. Andary, N. Ferrière, Annals of botany. 92, 4, 613-623 (2003)

20. A.M.P. Jones, P.K. Saxena, PloS one. 8, 10, 76802 (2013)

21. H. Krishna, R.K. Sairam, S.K. Singh, V.B. Patel, R.R. Sharma, M. Grover, L. Nain, A. Sachdev, Sci. Hortic. (Amsterdam). 118, 2, 132-138 (2008)

22. L.C. Huang, Y.L. Lee, B.L. Huang, C.I. Kuo, J.F. Shaw, Vit. Cell Dev. Biol. Plant. 38, 4, 358-365 (2002)

23. C.M.R. Lopez, H.S. Bravo, A.C. Wetten, M.J. Wilkinson, Mol. Breed. 25, 3, 501-516 (2010)

24. K.K. Modeste, M.T. Eliane, K. Daouda, S.A. Brahima, K. Tchoa, K.E. Kouablan, K. Mongomak, Aust. J. Crop Sci. 11, 25-31 (2017) 